\title{
COVID-19 screening at Emergency and Trauma Department, Sabah Women and Children's Hospital, Malaysia
}

\section{Introduction}

World Health Organisation (2020) reported that $14 \%$ of COVID-19 cases involved healthcare workers (HCW). Until $15^{\text {th }}$ December 2020, a total of 52,593 HCWs in Malaysia have undergone COVID-19 screening test, six days later, a total of 1880 positive cases were recorded (Abdullah, 2020). HCWs accounted for $2 \%$ of the total infected cases in Malaysia (Yu, 2021) with nurses making up the biggest proportion (Anand, 2020) as supported by the graph in this poster analysis which nurses are categorized under health professionals.. At the Sabah Women and Children's Hospital (HWKSS), the number of swabs taken for HCWs between May and November 2020 aggregated to 7,476 swabs, from which 167 positive cases were detected.
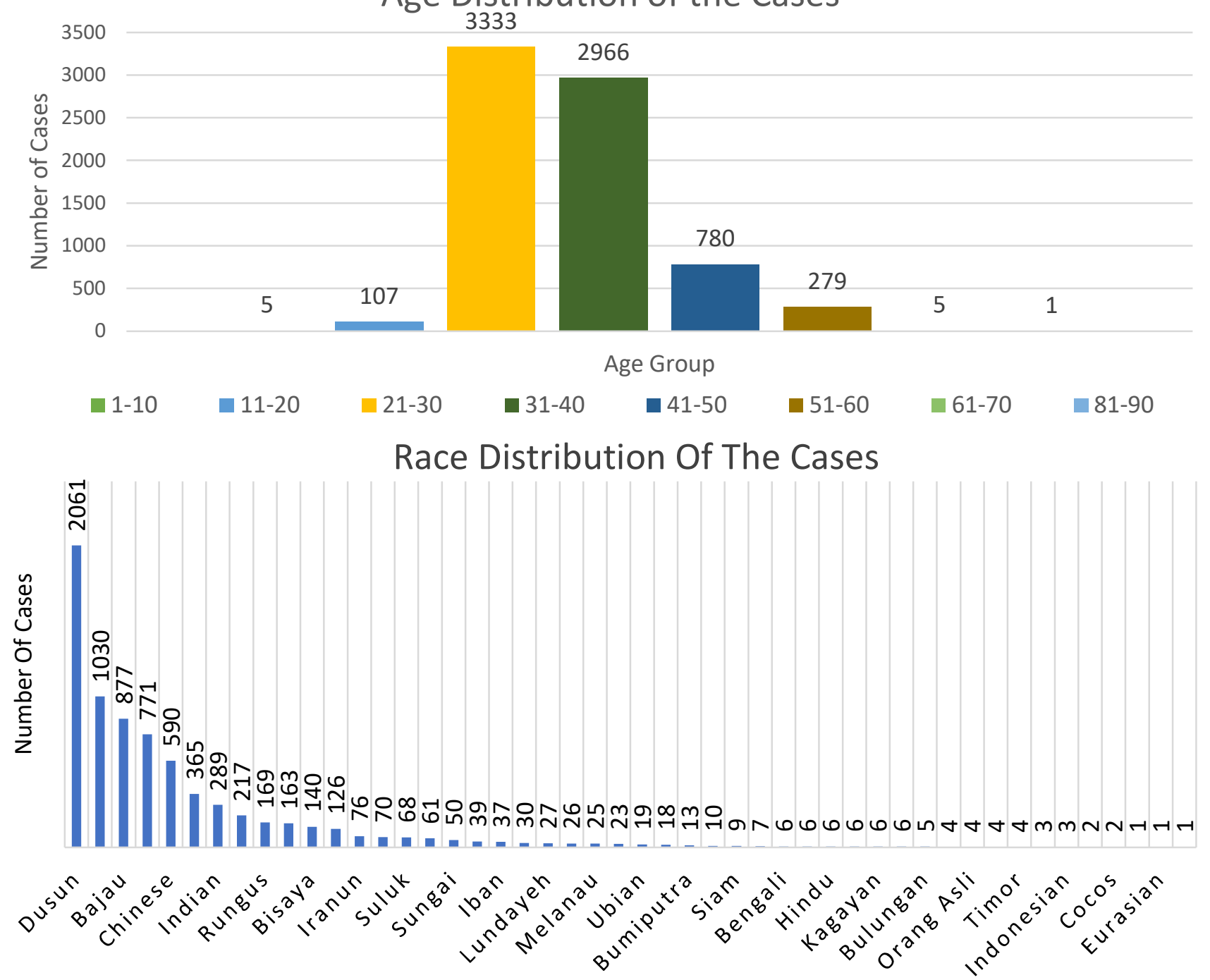

\section{Occupation Distribution Of The Cases}

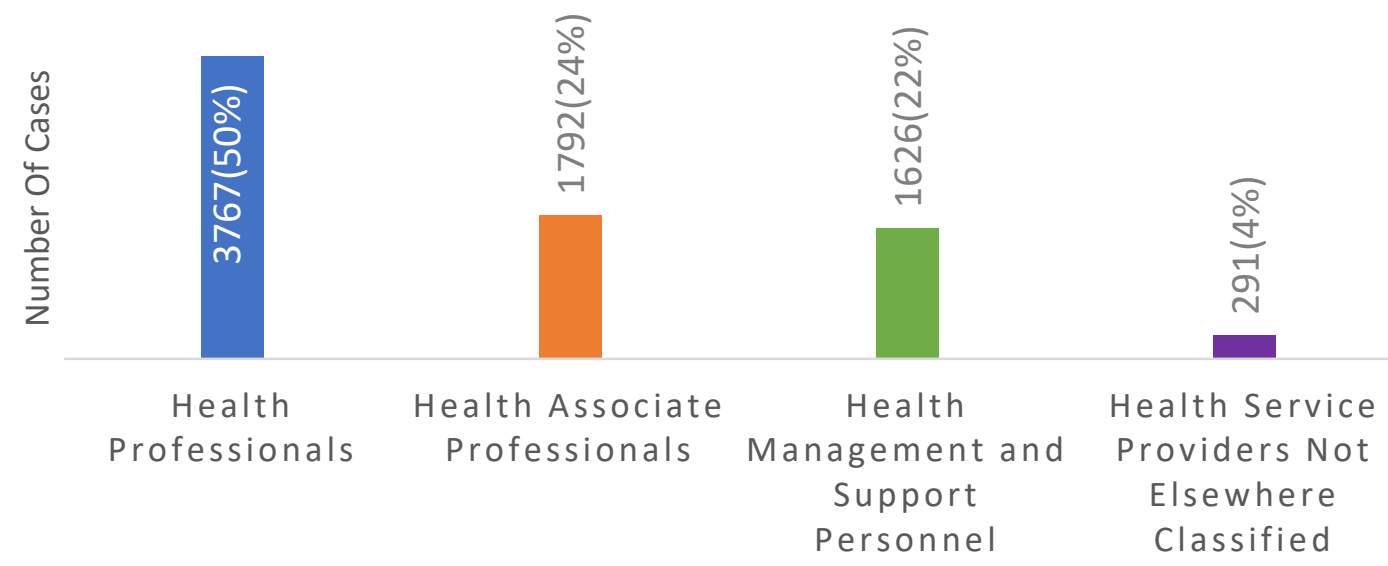




\section{Cases}

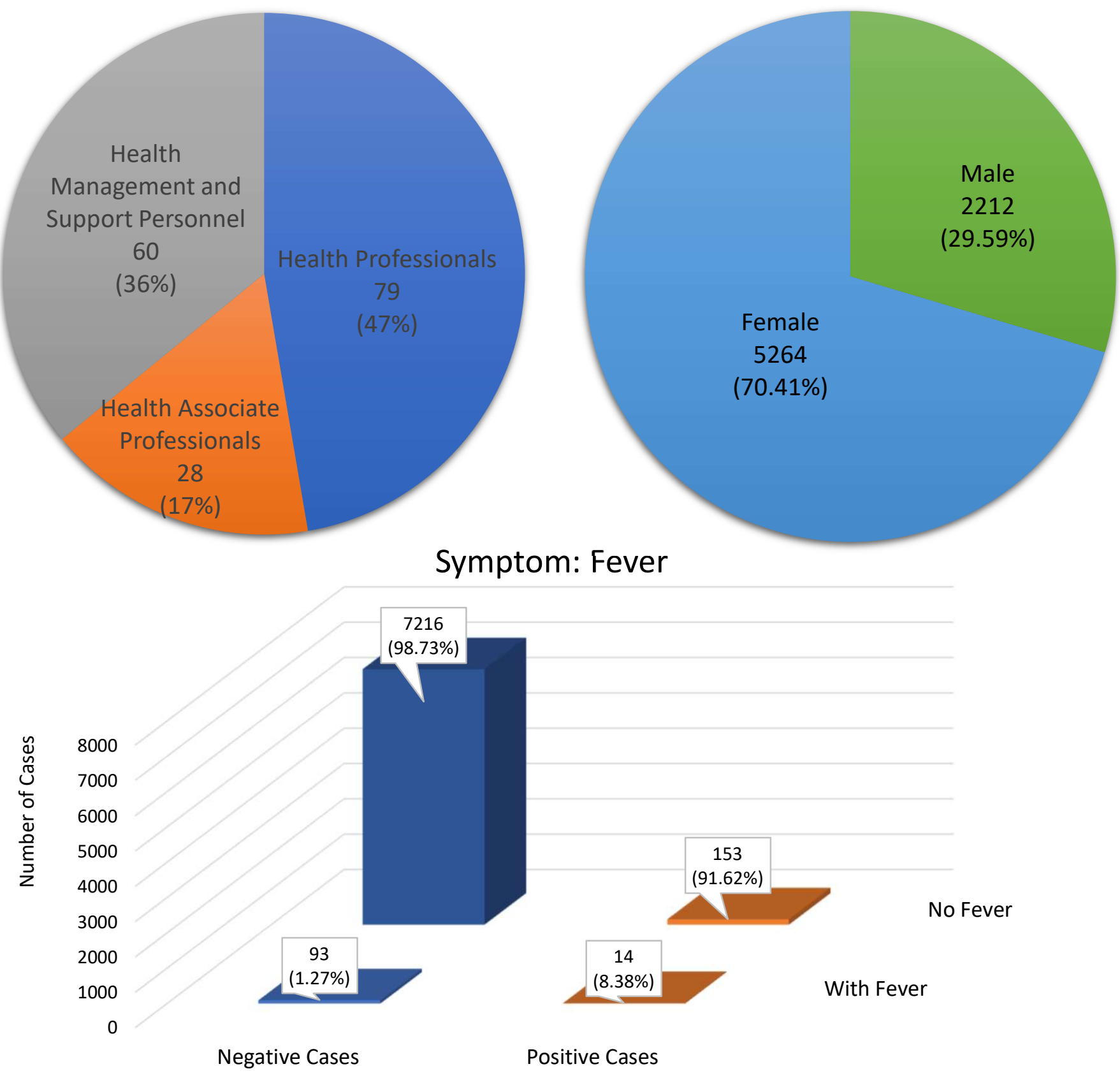

Symptom: Anosmia

No Anosmia With Anosmia

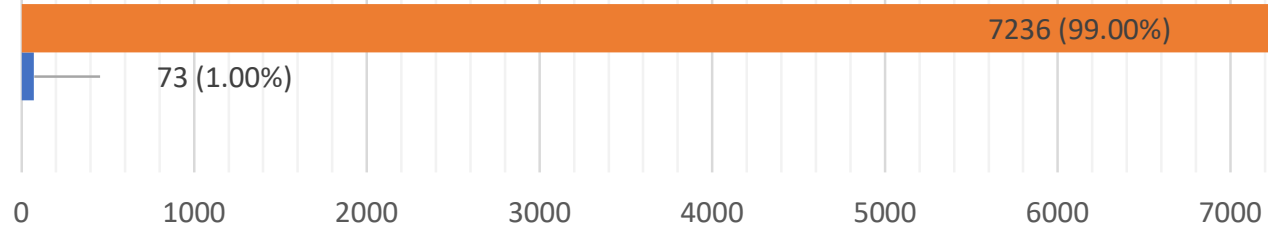




\section{Symptom: Shortness of Breath (SOB)}

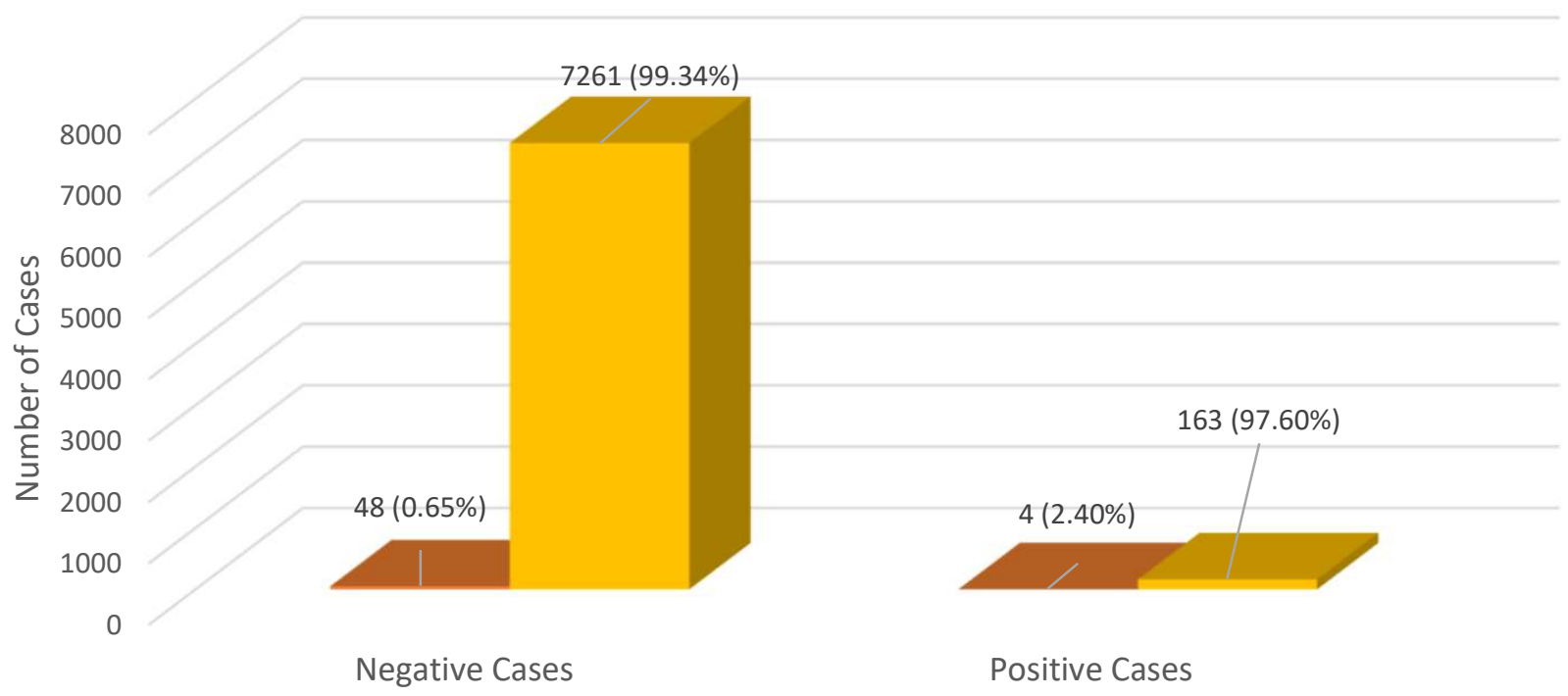

With SOB No SOB

\section{Contact Type}

$136(1.82 \%)$

$66(0.88 \%)$$$
0
$$

0

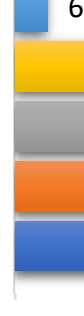

$500 \quad 1000 \quad 1500$
$\square$ Traveling history to high-risk area (without contact)
$\square$ No exposure (Baseline swab)
$\square$ Contact within health facility (During clinical duty)

$310(4.15 \%)$

\section{Positive Cases}

.

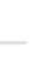




\section{Limitations}

- The statistics not only included HCWs from HWKKS, but also HCWs from other facilities deployed to HWKKS for testing to cope with the elevation of COVID-19 cases during the pandemic.

- The classification of HCWs in HWKKS is based on the international classification of health workers by World Health Organization (WHO). It is based on the International Standard Classification of Occupations (International Labour Office, 2012).

\section{References}

Abdullah, N.H. (2020, December 22). Kenyataan akhbar KPK 22 Disember 2020 - Situasi semasa jangkitan penyakit Coronavirus 2019 (COVID-19) di Malaysia. From the Desk of the DirectorGeneral of Health Malaysia. https://kpkesihatan.com/2020/12/22/kenyataan-akhbar-kpk-22disember-2020-situasi-semasa-jangkitan-penyakit-coronavirus-2019-covid-19-di-malaysia/

Anand, R. (2020, December 18). Malaysia faces coronavirus outbreak among health care workers as active cases hit all-time high. The Straits Times. https://www.straitstimes.com/asia/se-asia/malaysia-facescoronavirus-outbreak-among-health-workers-as-active-cases-hit-all-time

International Labour Office. (2012). International standard classification of occupations 2008 (ISCO-08): Structure, group definitions and correspondence tables. International Labour Office. https://www.ilo.org/global/publications/ilo-bookstore/order-online/books/WCMS 172572/lang-en/index.htm

World Health Organization. (2010). Classifying health workers: Mapping occupations to the international standard classification. Geneva: World Health Organization. https://www.who.int/hrh/statistics/Health workers classification.pdf

World Health Organization. (2020). Prevention, identification and management of health worker infection in the context of COVID -19: interim guidance, 30 October 2020 (No. WHO/2019nCoV/Hipifications/2020.1). World Health Organization.

Yu, C.W. (2021, January 20). Balancing health workers' safety and patient care. New Straits Times. https://www.nst.com.my/opinion/columnists/2021/01/658893/balancing-health-workers-safety-andpatient-care 